\title{
Implementation of an older person's nurse practitioner in rural aged care in Victoria, Australia: a qualitative study
}

\author{
Kaye Ervin ${ }^{*}$, Carol Reid, Anna Moran, Cynthia Opie and Helen Haines
}

\begin{abstract}
Background: There are staff shortages nation-wide in residential aged care, which is only predicted to grow as the population ages in Australia. The aged care staff shortage is compounded in rural and remote areas where the health service workforce overall experiences difficulties in recruitment and retention. There is evidence that nurse practitioners fill important service gaps in aged care and rural health care but also evidence that barriers exist in introducing this extended practice role.

Methods: In 2018, 58 medical and direct care staff participated in interviews and focus groups about the implementation of an older person's nurse practitioner (OPNP) in aged care. All 58 interviewees had previously or currently worked in an aged care setting where the OPNP delivered services.

The interviews were analysed using May's implementation theory framework to better understand staff perceptions of barriers and enablers when an OPNP was introduced to the workplace.

Results: The major perceived barrier to capacity of implementing the OPNP was a lack of material resources, namely funding of the role given the OPNP's limited ability to self-fund through access to the Medicare Benefits Schedule (MBS). Staff perceived that benefits included timely access to care for residents, hospital avoidance and improved resident health outcomes.

Conclusion: Despite staff perceptions of more timely access to care for residents and improved outcomes, widespread implementation of the OPNP role may be hampered by a poor understanding of the role of an OPNP and the legislative requirement for a collaborative arrangement with a medical practitioner as well as limited access to the MBS. This study was not a registered trial.
\end{abstract}

Keywords: Rural aged care, Nurse practitioner, Implementation

\section{Background}

Similar to other countries, Australia is facing unprecedented challenges to meet the growing healthcare needs of an ageing population. Currently, just over 250000 people utilise aged care services [1], but it is predicted that by 2050, over 3.5 million Australians will be accessing aged care services annually [2]. Despite this growth in demand, general medical practitioners in Australia report intention to decrease or stop providing services to people in residential aged care [3]. Workforce shortages in aged care settings are well known, in addition to the difficulty in recruiting the skill mix required to meet the increasingly complex

\footnotetext{
* Correspondence: Kaye.Ervin@ncnhealth.org.au

University of Melbourne, Melbourne, Australia
}

needs of ageing people. Challenges in meeting workforce requirements for safe and quality care are amplified outside metropolitan areas, particularly in remote areas [4]. Nurse practitioners are well placed to fill this widening gap, but to be successful, these roles need to be promoted with managers and decision-makers who may have a limited understanding of the importance of the clinical support offered by the extended scope of practice [5].

Health workforce shortages across all disciplines in rural Australia have necessitated the implementation of a range of workforce models, including the use of nurse practitioners, as a strategy to improve access, efficiency and quality of care for patients [6]. Currently, there are around 1745 endorsed nurse practitioners in Australia,

(c) The Author(s). 2019 Open Access This article is distributed under the terms of the Creative Commons Attribution 4.0 International License (http://creativecommons.org/licenses/by/4.0/), which permits unrestricted use, distribution, and 
including 365 in the state of Victoria, working across a variety of specialty areas [7] including aged care.

Nurse practitioners are defined as registered nurses who possess expert knowledge, complex decision-making skills and clinical competence [8] with legislated expanded scope of practice to include diagnosis, prescribing and referral. In 2010, nurse practitioners were granted access to the public health insurance scheme (Medicare) subject to a collaborative arrangement with a medical practitioner [9] .

With access to Medicare, specialist aged care services are being increasingly provided by nurse practitioners [2] using various models of care, including independent private practice, outreach services from acute settings or working from community-based organisations. Nurse practitioners are providing services to all health settings, especially in rural and remote locations where there are workforce and skills shortages [5].

There is a paucity of evidence that is reported in the national and international literature regarding implementation of the nurse practitioner role, in particular in rural areas. Little is known about the challenges faced by owners or managers, or direct care staff, of rural residential aged care services in introducing a nurse practitioner role. The purpose of this study was to explore perceived barriers and enablers to implementing an older person's nurse practitioner (OPNP) from the perception of residential aged care staff in rural aged care settings. The overall aim of the research is to describe the mechanisms which may be required for successful implementation of an OPNP role in rural residential aged care settings.

\section{Implementation framework}

The theoretical framework chosen for the study was May's implementation theory [10]. May's theory considers the complex, multi-dimensional aspects of health services in relation to the introduction of a new intervention and provides a structure to better examine what does or does not work. Briefly, May's implementation theory focuses on four main themes; capability, capacity, potential and contribution. These themes are defined as

1) Capability-the capability of agents to operationalise a complex intervention which depends on its workability and integration within a social system;

2) Capacity-the incorporation of a complex intervention within a social system which depends on an agent's capacity to cooperate and coordinate their actions;

3) Potential-the translation of capacity into collective action which depends on an agent's potential to enact the complex intervention; and

4) Contribution - the implementation of a complex intervention which depends on an agent's continuous contributions that carry forward in time and space.

In the context of this study, agents are the staff of the residential aged care facility (RACF), including clinical care staff, general practitioners (GPs) and managers. The complex intervention is the OPNP role and scope of practice. The social system is the RACF.

\section{Methods \\ Design}

This study employed a qualitative research design using semi-structured interviews. The study scope was defined as sites where an OPNP delivered services, targeting health service staff associated with the implementation and delivery of the OPNP extended scope of practice. A purposive sample of health service management, care managers, nursing and care staff and GPs was sought. Qualitative data were generated through both focus groups and individual face to face or telephone interviews.

\section{Recruitment}

Participant recruitment focussed on six [6] RACFs where the OPNP was contracted to deliver services. The participants were recruited through direct contact by both phone and email. Mutually suitable interview times and dates were then scheduled. All interviews occurred at participants' workplaces in 2018. A brief description of the project was provided to gauge interest. Those who expressed interest in participating were provided with a plain language statement and a consent form to sign.

\section{Intervention}

Each of the RACFs in the study contracted the OPNP privately, with varying contracted hours (shown in Table 1). In addition, the period of time that the OPNP had been delivering services differed between sites as also shown in Table 1. As well as a collaborative agreement with GPs, at each site the OPNP is mentored by a geriatrician. The OPNP scope of practice includes access to diagnostics (such as radiology and pathology), prescribing (with limited access to the Pharmaceutical Benefits Scheme (PBS) depending on approval) and referral to specialist medical professionals. Access to the Medicare Benefits Schedule (MSBS) ${ }^{1}$ for payment is limited and varies according to clinical practice endorsement. The OPNP provided the research team with an estimate of the

\footnotetext{
${ }^{1}$ Medicare is Australia's government health care system. Employed people pay a Medicare levy as part of their income tax to fund the system for all Australians requiring medical treatment. Governmentfunded medical services are listed on the MBS. The government authorises which practitioners can claim the government funding for providing services. Most services provided by a medical practitioner are funded wholly or partly by Medicare. Nurses and allied health practitioners have restricted access to the MBS for providing services.
} 
Table 1 Recruitment sites

\begin{tabular}{|c|c|c|c|c|c|c|}
\hline Sites & RACF service type & $\begin{array}{l}\text { Bed numbers } \\
\text { available }\end{array}$ & $\begin{array}{l}\text { Services available in } \\
\text { township } \\
\text { (town population) }\end{array}$ & Privately contracted hours of OPNP & $\begin{array}{l}\text { Approximate } \\
\text { percentage of } \\
\text { residents with GP } \\
\text { collaborative } \\
\text { agreement }\end{array}$ & $\begin{array}{l}\text { Period of time } \\
\text { of service } \\
\text { delivery }\end{array}$ \\
\hline Site 1 & Public sector-2 facilities & $\begin{array}{l}36 \\
15\end{array}$ & $\begin{array}{l}\text { Acute service } \\
\text { Urgent Care } \\
\text { Allied health } \\
\text { Community services } \\
\text { Medical clinic } \\
\text { (population = } 1082 \text { ) }\end{array}$ & $8 \mathrm{~h}$ per week & $100 \%$ & 1.5 years \\
\hline Site 2 & Not for profit & 146 & $\begin{array}{l}\text { Regional centre with all } \\
\text { medical and allied health } \\
\text { services } \\
\text { (population = } 28 \text { 559) }\end{array}$ & $\begin{array}{l}8 \mathrm{~h} \text { per week-divided } \\
\text { into two 4-h sessions }\end{array}$ & $50 \%$ & 6 years \\
\hline Site 3 & Not for profit & 69 & $\begin{array}{l}\text { Regional centre with all } \\
\text { medical and allied health } \\
\text { services } \\
\text { (population = } 28 \text { 559) }\end{array}$ & $\begin{array}{l}12 \mathrm{~h} \text { per week-divided } \\
\text { into three } 4 \text {-h sessions }\end{array}$ & $60 \%$ & 6 years \\
\hline Site 4 & Public sector & 14 & $\begin{array}{l}\text { Acute service } \\
\text { Urgent Care } \\
\text { Community services } \\
\text { Medical clinic } \\
\text { (population = 406) }\end{array}$ & $8 \mathrm{~h}$ per month & $100 \%$ & 2.5 years \\
\hline Site 5 & Public sector-2 facilities & $\begin{array}{l}30 \\
32\end{array}$ & $\begin{array}{l}\text { Acute service } \\
\text { Operating theatre } \\
\text { Radiology } \\
\text { Pathology } \\
\text { Urgent care } \\
\text { Community services } \\
\text { Medical clinic } \times 2 \\
\text { (population }=4 \text { 477) }\end{array}$ & $\begin{array}{l}8 \mathrm{~h} \text { per fortnight—divided } \\
\text { into } 4 \mathrm{~h} \text { per week }\end{array}$ & $100 \%$ & 1 year \\
\hline
\end{tabular}

percentage of older people receiving service at each site (Table 1). Service delivery percentages vary over time according to admission and discharge (death) of older people in the facility and their treating GP.

\section{Settings}

This study involved five geographical sites (one regional and four rural), in Victoria, Australia. A description of the de-identified recruitment sites are shown in Table 1 with an accompanying description of the services available in the location and overall population of the location. Public sector RACFs are wholly funded by the government, and not for profit RACFs receive partial funding and as the name suggests are provided by charitable organisations not private organisations that aim to generate a profit.

\section{Interviews}

The interviews and focus groups were conducted by two female researchers in 2018. One researcher is a nurse (CO) and one a social worker (CR). Both have qualitative research experience. Some interview participants at one rural site were known to one researcher (CR). A copy of the interview schedule is available from the corresponding author. In brief, participants were asked two key questions:

- What is the experience of implementing an OPNP?

- What are the enablers and barriers to implementing an OPNP in RACFs?

Sub-questions included understanding of the NP role and management motivation for implementation.

\section{Data analysis}

Participant interviews were initially grouped by site, because of the dynamic element of context in implementation theory. A number of the GP participants worked across more than one site; therefore, interviews were re-grouped and GPs assigned as a separate group. Final analysis was undertaken on six groups. The final de-identified groupings and their composition and total number are shown in Table 2.

All transcripts were analysed by hand. Preliminary, first cycle coding used process and values coding as an elemental method to attune researchers to participants' perspectives and actions [11]. This was undertaken by three researchers (CR, HH, AM). Second cycle coding (theoretical coding) was undertaken by two researchers (KE and 
Table 2 Final analysis groups and composition

\begin{tabular}{|c|c|c|}
\hline Site or group & Description & Total participant number by site \\
\hline Site 1 & $\begin{array}{l}\text { Health service focus group } \\
\text { Director of clinical services } \\
\text { Quality and risk manager } \\
\text { Medical clinic staff focus group }\end{array}$ & 10 \\
\hline Site 2 & $\begin{array}{l}\text { RACF focus group } \\
\text { RACF clinical care coordinators } \times 2 \\
\text { Registered nurse RACF } \\
\text { Team leader RACF }\end{array}$ & 8 \\
\hline Site 3 & $\begin{array}{l}\text { Registered nurse RACF } \times 2 \\
\text { Enrolled nurse } \times 2 \\
\text { RACF manager } \\
\text { RACF focus group }\end{array}$ & 10 \\
\hline GP group & $\begin{array}{l}\text { GPs } \times 4 \\
\text { GP focus group sites } 2 \text { and } 3\end{array}$ & 7 \\
\hline Site 4 & $\begin{array}{l}\text { Registered nurse health service } \times 2 \\
\text { Director of clinical services } \\
\text { Registered nurse medical clinic }\end{array}$ & 4 \\
\hline Site 5 & $\begin{array}{l}\text { RACF focus group } \times 2 \\
\text { RACF clinical care coordinators } \times 2 \\
\text { Director of RACF } \\
\text { RACF manager } \\
\text { Health service manager } \\
\text { Health service director of clinical services }\end{array}$ & 19 \\
\hline
\end{tabular}

CR) utilising May's implementation theory framework [10] (see Table 3 in "Results" for a concise description of this theory). Codes from implementation theory domains were generated and sub-categories applied to tracts in text that reflected these concepts. This enabled the whole dataset to be indexed into domains and descriptive subcategories. Content analysis [12] of positive and negative perceptions allowed identification of enablers or barriers to implementation.

\section{Implementation theory framework}

It is not enough to know if a health intervention is effective; it is also necessary to understand why an intervention works, how, for whom and in what context. Implementation science is aimed at mobilising theories, concepts and methods to better understand what, why and how interventions work in the "real world" [13]. To be more precise in the description of the analysis of our qualitative study, it was important to better describe the content and ongoing processes of implementation of the OPNP role for fidelity of the findings. May's implementation theory provided a framework to index the domains and sub-categories for a more thorough understanding of what worked and how it worked. Implementation theory and frameworks are increasingly being used in contextual analysis and research designs in order to have a greater understanding of how to implement health interventions and policy. The World Health Organization encourages the use of implementation science to create better adaption and adoption of health interventions [14].

\section{Results}

Fourteen hours and fifteen minutes of voice recorded material was transcribed verbatim. Transcripts were returned to participants who consented to check for authenticity.

The findings presented are from across all sites, and categorised as barriers and enablers to implementation of an OPNP in residential aged care. The findings are presented under the domains of implementation theory: capability, capacity, potential and contribution. Each of these domains is then described by sub-categories and participant quotes to better illustrate how barriers and enablers were derived from positive and negative perceptions.

There were equivalent amounts $(n=77)$ of positive and negative perceptions illustrating barriers and enablers regarding capability as a measure of implementation. At all sites, the legislative requirement of an OPNP working in a collaborative arrangement with a GP was perceived as a barrier, except at the smallest health service, where it was considered to work well. A lack of information and partnership with staff regarding the introduction of the OPNP role and scope of practice was perceived negatively and translated as a barrier for implementation of the role. Field notes illustrate that staff at some sites felt undermined by the introduction of the OPNP, that their skills were insufficient or that some "need" had been identified but had not been communicated to them. Integration into practice also embodies assumptions about an intervention and its expected value.

Positive $(n=262)$ and negative $(n=267)$ perceptions of capacity to implement the OPNP role were identified in 


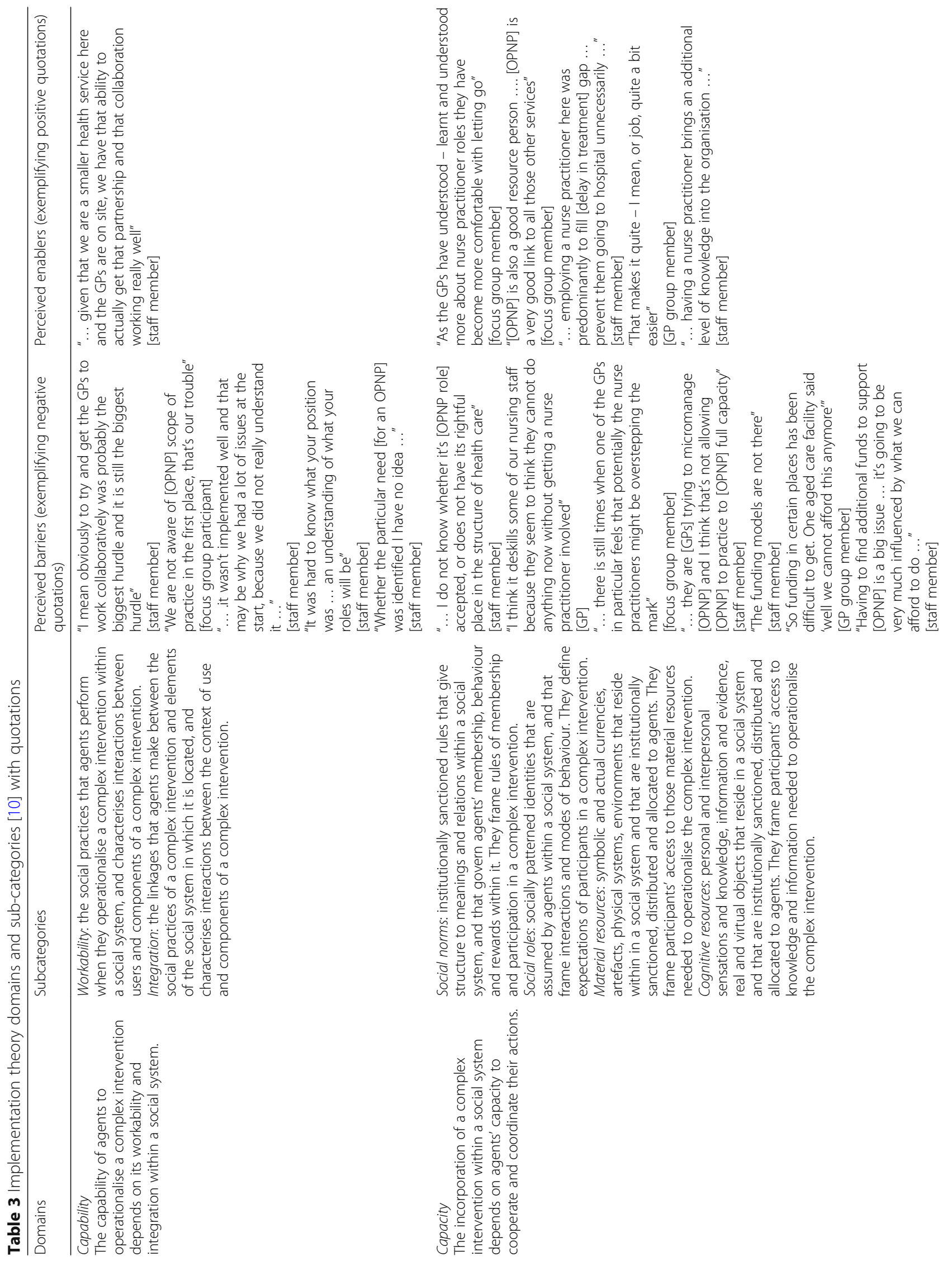




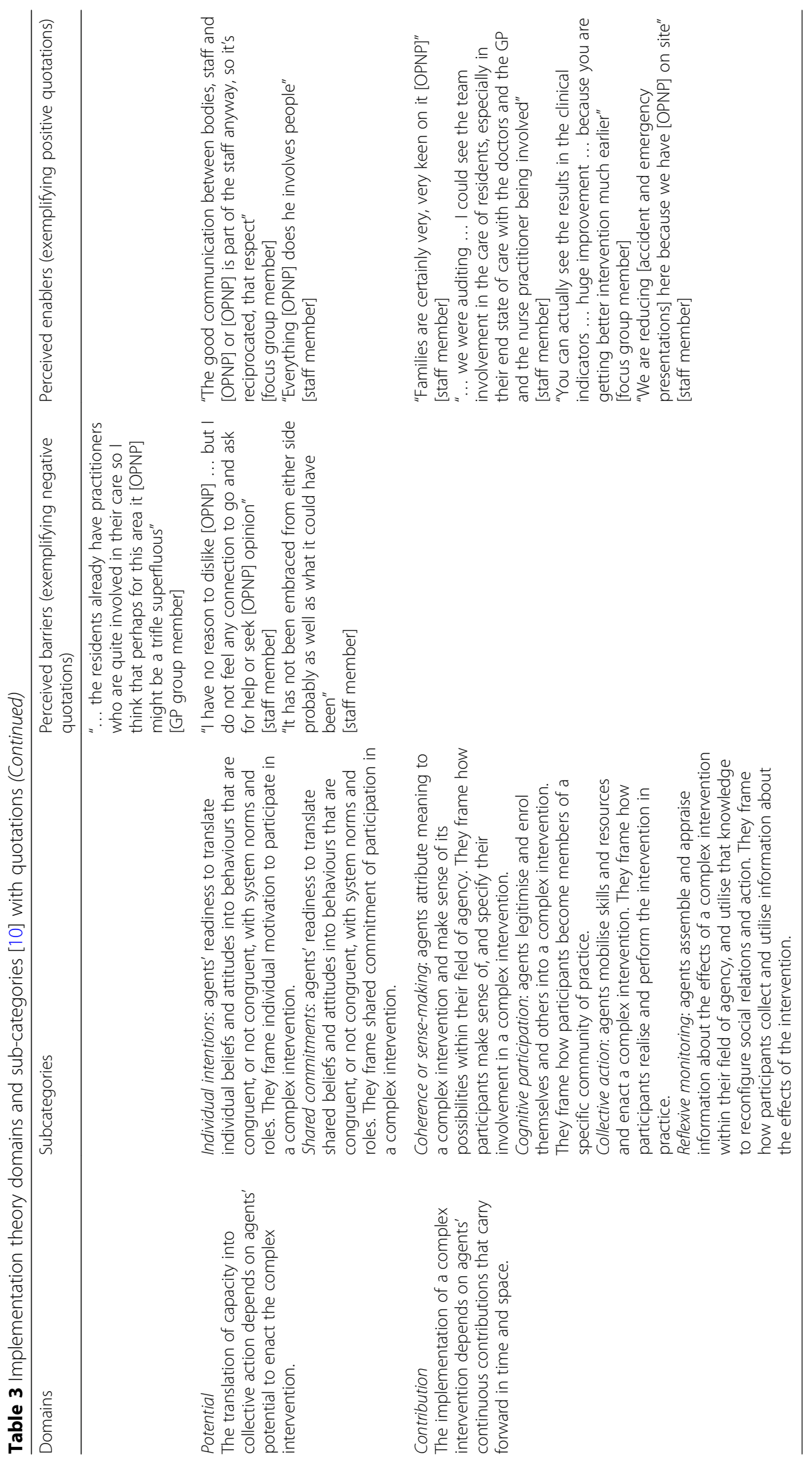


the analysis. Social roles and material resources were the most dominant feature perceived as barriers and enablers. Material resources were perceived as contingent as an enabler to employ an OPNP. Social roles, the interpersonal relationship between the OPNP and GPs and the OPNP and RNs, were frequently perceived negatively and therefore identified in the analysis as a barrier to implementation of the OPNP role, though this was also identified as something that ameliorated over time.

The potential to implement the OPNP role when analysed using implementation theory was predominantly negative $(n=28)$ when compared to positive perceptions $(n=12)$ and therefore collectively identified as a barrier. The two quotations exemplifying enablers relate to subcategory of shared commitment.

Reflexive monitoring in implementation of the OPNP role was identified as an enabler in terms of contribution, with multiple positive perceptions of the OPNP role when auditing outcomes of resident care with three quotes illustrating this. Overall, there were 29 positive comments related to contribution.

\section{Discussion}

\section{Capability}

Workability as a concept of implementation of an older person's nurse practitioner (OPNP) was perceived as problematic at almost all the research sites involved in this study. In particular, the legislated requirement for a collaborative arrangement between nurse practitioners and medical practitioners was viewed negatively. A previous Australian study [9] found that success of the collaborative arrangement relied on the personal commitment and willingness of both NPs and GPs. Schadewaldt et al. [9] also found more complex problems with the legislative requirements, such as disadvantages for NPs if the local infrastructure did not include a visiting GP or overlapping of roles and blurring of professional boundaries and legal liability. Collaboration is also influenced by interpersonal differences of NPs and GPs, which was found in this study and reported in a systematic review of NP experiences [15]. There have been allegations that the poor uptake of NP training and implementation of the role can be ascribed to medical dominance and a power struggle between nurses and GPs about professional roles [16]. It is a legislative prerequisite for NPs to have a collaborative agreement with a medical practitioner in order to access Medicare subsidy schemes. The Medicare Benefits Schedule Review Taskforce [17] is currently reviewing the requirement for NPs to have a collaborative agreement with a medical practitioner. Revision of this legislation could remove a significant barrier to implementation of OPNP roles found in this study.
Barriers to integration of the OPNP role was reported at many of the study sites and focused predominantly on staff reporting a poor knowledge of the NP role and scope of practice. Other studies $[17,18]$ also cite the paucity of healthcare professionals understanding of the NP role, which in turn impacted on NPs being able to work at their full scope of practice. Dwyer et al. [19] report that knowledge of and prior exposure to the NP role was a contributing factor to successful implementation of the role, which is also supported by the findings of a more recent study [5]. May [10] warns that successful implementation of any intervention is threatened if the capacity of staff to employ it is confounded. To put it simply, successful implementation of the OPNP requires aged care staff to have a good understanding of the extended scope of practice. One study [20] reported that holding meetings with staff to clarify questions and dispel concerns about NPs was key to successful implementation. The reported paucity of staff knowledge of the NP role suggests that NPs themselves have a responsibility to ensure co-workers have a good understanding of their scope of practice and the limitations of their role. It can be assumed that this is even more crucial when OPNPs are employed at RACFs where staff have had no previous exposure to the NP role. Staff must feel engaged during the implementation process to ensure an understanding that the new position is "adding value" rather than "replacing" existing roles.

\section{Capacity}

Staff of the RACFs participating in this study reported positive perceptions about the benefits for staff and residents afforded by the availability of an OPNP, while being largely negative about the financial ability to employ them and the blurring of professional boundaries.

Dwyer et al. [19] cite multiple studies that demonstrate holistic NP-led models of care that engender a positive impact upon residents' quality of life and health outcomes, in addition to reducing hospital admissions, which was also found in this study. In this study, staff attributed this outcome to the availability of the OPNP to treat residents, rather than waiting extended periods of time for a GP to be available. This is supported by the findings of Dwyer et al. that early intervention by NPs led to timely treatment and subsequent hospital avoidance which met the needs of the resident, family and RACF staff.

Currently, NPs in Australia have limited access to the MBS subsidy schemes. While medical practitioners have access to remuneration for hundreds of MBS items, NPs are limited to four items and reimbursement is at $85 \%$ of the scheduled fee. These fiscal constraints mean that NPs either have to charge residents directly or be employed by an organisation for service delivery. Even 
access to the four items on the MBS is dependent upon a collaborative arrangement with a medical practitioner. NPs are therefore reliant on organisations funding their positions within the organisations' own budgetary constraints. The participants in this study who were responsible for employing the OPNP stated that they did so because of prior exposure to the role and scope of the $\mathrm{NP}$ and perceived that the associated costs of the NP wages translated into improved quality of care for the services delivered. The implication of this is that the capacity of a RACF to employ an OPNP is reliant on material resources for both its introduction and sustainability. May [10] proposes that capability, particularly normalisation into practice, is threatened through poor resourcing or uncertain sustainability. A review of international studies found that one reason for underutilisation of NPs included a lack of financial support [21]. The most recent Australian study [5] found that even when funding for a NP role was available, it was not recurrent, in which case the positions went unfilled. Another Australian study found that the difficulties faced by NPs in generating their own income decreased their chances of employment [20]. The Medicare Benefits Schedule Review Taskforce [17] may remove this financial barrier to implementation; if access to an increased number of MBS items occurred, NPs could be better remunerated for their services, negating the need to be employed by RACFs as private providers.

The blurring of professional boundaries in the NP scope of practice is a very real concern, particularly regarding legal liability. Some participants in this study expressed concern and uncertainty about the implications for their scope of practice once the OPNP was introduced. It was perceived that their scope would be reduced, or to continue to perform tasks in their usual role would "step on toes". Other participants also expressed that the introduction of the OPNP resulted in deskilling of the usual staff, who became reluctant to work to their full scope of practice due to uncertainty about what was now acceptable. This could be resolved through better education of existing staff [20] or adhering to important principles of workforce change [22] prior to implementation of the OPNP role.

Some GP participants in this study perceived that they were ultimately legally responsible for the care of residents. This may be perpetuated by the legislated collaborative requirement. Although professional guidelines in Australia clearly state that individual practitioners are responsible for their own actions [23, 24], contrasting perceptions are demonstrated in practice. This study supports the finding of Schadewaldt et al.'s study [20] that medico-legal liability is unclear when patient care is shared between NPs and medical practitioners. There needs to be clear legislation to resolve this discrepancy with shared care and for NPs to be truly independent and autonomous in their delivery of care and treatment in RACFs.

\section{Potential}

In this study, the sub-categories of potential, namely collective and individual commitment, were largely perceived negatively. This may stem from poor understanding of the OPNP role and scope of practice. It is difficult to support a role and model of care when there is little conceptual understanding of the purpose of the role and the processes and limitations of utilising the role. It is difficult to form a discussion around this generally given the many different models of NP services. In this study, and for OPNPs who provide services on a contractual basis to RACFs, potential could be facilitated by prioritising information about the NP role through staff education and communicating the clear aim of introducing the role. Dwyer et al. [19] propose that potential develops over time with increased exposure and building trust between stakeholders and the OPNP. It is also proposed that building trust, particularly in rural areas, is not simply acceptance of formal qualifications but more about an unwritten need to "prove yourself" [19]. Trust was exemplified in this study, where participants at sites 2 and 3 (where the OPNP had been practising for longer) expressed far more positive perceptions about the role and the individual OPNP, as well as an intention to maintain the OPNP service. The implication of this finding is that caution should be exercised by RACFs to ensure the individual NP is a good "fit" with the organisation.

Conversely, Dwyer et al. [19] also found that NPs have the unique potential to facilitate collective and individual commitment by their knowledge of dual professions, systems and close professional relationship with residents, which enabled them to become a conduit between groups. Findings from this study also supports the findings of Dwyer et al.'s study [19] that RACF staff were more confident discussing resident care with a NP than a GP, because they were nurses and therefore "speak the same language". However, this finding was only true in this study at two sites where the OPNP had practised for a greater length of time, suggesting this was also related to time or trust.

\section{Contribution}

At the study sites where reflexive monitoring had occurred through auditing of impact of the role compared with resident outcomes, perceptions of contribution were positive. Comments related to contribution were not elicited at one site; interestingly, that site had been utilising the OPNP for the least amount of time, potentially indicating that the length of service provision had 
not yet allowed reflexive monitoring. At all other sites where reflexive monitoring had occurred, comments reflected perceived benefits. Like other studies [25, 26], this study found that staff perceived the implementation of the OPNP role had a direct effect on improved quality of care. In this study, staff perceptions were based on the results of auditing quality outcomes such as reduced hospital transfers. This finding implies that implementation of an OPNP in RACFs may translate into costeffective savings for the entire health system.

Other studies $[18,27]$ found that a poor understanding of the NP role influenced consumers' decision to see a NP. In this study, there was demand from residents to see the NP due to awareness of the role. Demand was not able to be met because the resident's treating GP did not have a collaborative agreement with the NP. Demand for NP services has not been previously reported in the literature, so consumer demand for an OPNP is a unique finding of this study. This finding has important implications for aged care policy makers, with a focus on increasing choices for older people ubiquitous in policy, legislation and standards of care. Demand for an OPNP should also be considered in light of the decreasing access to medical services in RACFs and the intention of Australian GPs to decrease or cease services to RACFs [3].

The benefit of using May's implementation theory [10] for this study was an interpretation of agent perceptions across six RACF sites regarding the introduction of an OPNP model of care. Using implementation theory as a framework when considering new models of care in any context is crucial in all stages of planning from needs assessment, theory of change development to theory of action (implementation).

A limitation of this study was that interviews were conducted only with staff of RACFs and did not include perceptions of residents or their families. This limitation may have missed an opportunity to further explore consumer demand for OPNP services. Additionally, the study was conducted in rural and regional RACFs and the findings may not be transferable to metropolitan settings.

\section{Conclusion}

Implementation of any health care intervention is complex, and success is reliant on multiple factors. This study was undertaken to explore all the complex factors related to implementing an OPNP in RACFs in rural Victoria in order for RACF managers to understand the resources and processes that may be required for successful implementation and for policy makers to understand the perceived barriers and thereby address them. The Medicare Benefits Schedule Review Taskforce may provide solutions to the major barriers if the recommendations for greater access to the MBS for NPs, and review of the collaborative arrangement between NPs and medical practitioners are fully considered. Both recommendations would resolve perceived barriers found in this study, predominantly remuneration for NP services and reliance on a consenting GP for access to and professional collaboration for treatment of people in RACFs.

\section{Abbreviations \\ GP: General practitioner; MBS: Medicare Benefits Schedule; NPS: Nurse practitioners; OPNP: Older person's nurse practitioner; RACF: Residential aged care facility; RN: Registered nurse}

\section{Acknowledgements}

The authors wish to thank everyone who consented to interviews and contributed to the study.

\section{Authors' contributions}

KE contributed to the research design, data analysis and manuscript writing. $\mathrm{CR}$ contributed to the research design, data collection and manuscript writing. AM contributed to the data analysis and manuscript writing. $\mathrm{HH}$ contributed to the data analysis and manuscript writing. CO contributed to the data collection and manuscript editing. All authors read and approved the final manuscript.

\section{Funding}

This research has been supported by the Australian Government Department of Health through the Rural Health Multidisciplinary Training Programme.

\section{Availability of data and materials}

A copy of the interview schedule and de-identified transcripts are available from the corresponding author. Due to the context of the study in small rural RACFs, original transcripts of interviews are withheld to protect participants' identities.

\section{Ethics approval and consent to participate}

The University of Melbourne Human Research Ethics Advisory Group provided approval for the study. All participants returned signed consent forms.

\section{Consent for publication}

All authors agree to the content and consent to publication.

\section{Competing interests}

The authors declare they have no competing interests.

Received: 16 June 2019 Accepted: 10 September 2019

Published online: 01 November 2019

\section{References}

1. Australian Government. Australian Institute of Health and Welfare. GEN aged care data; 2018. [cited 2019 Jan 3]. Available from: http:www.genagedcaredata.gov.au

2. Roche $T$, Gardner $G$, Jack $L$. The effectiveness of emergency nurse practitioner service in the management of patients presenting to rural hospitals with chest pain: a multisite prospective longitudinal nested cohort study. BMC Health Serv Res. 2017;17(445). https://doi.org/10.1186/s12913017-2395-9.

3. Australian Medical Association. 2017 AMA aged care survey report; 2018. [cited 2019 Jan 3]. Available from: http:www.ama.com.au

4. Commonwealth of Australia. A matter of care Australia's aged care workforce strategy, aged care workforce strategy taskforce; 2018.

5. Smith T, McNeil K, Mitchell R, Boyle B, Ries N. A study of macro-, meso- and micro- barriers and enablers affecting extended scopes of practice: the case of rural nurse practitioners in Australia. BMC Nurs. 2019;18(14). https://doi. org/10.1186/s12912-019-0337-z. 
6. Wilson $\mathrm{K}$, Cameron $\mathrm{P}$, Jennings N. Emergency nurse practitioners: an underestimated addition to the emergency care team. Emerg Med Australas. 2008;20(6):453-5.

7. Nursing and Midwifery Board of Australia. Registrant data. Reporting period: 1 July - 30 September 2018; 2018. [cited 2019 Jan 2]. Available from: http: www.ahpra.com.au

8. International Council of Nurses (ICN). Definition and characteristics of the role. International Council of Nurses Nurse Practitioner / advanced practice nursing network; 2016. [cited 2019 Jan 2]. Available from: http:// international.aanp.org/Practice/APNRoles

9. Schadewaldt V, Mclnnes E, Hiller J, Gardner A. Experiences of nurse practitioners and medical practitioners working in collaborative practice models in primary healthcare in Australia - a multiple case study using mixed methods. BMC Fam Pr. 2016;17:99. https://doi.org/10.1186/s12875016-0503-2.

10. May C. Towards a general theory of implementation. Implement Sci. 2013; 8(18) Available from: http://www.implemetationscience.com/content/8/1/18.

11. Saldana J. The coding manual for qualitative researchers. Thousand Oaks: SAGE Publications Ltd.; 2016.

12. Hodder I. The interpretation of documents and material culture. Thousand Oaks: Sage; 1994. p. 155.

13. Peters $\mathrm{D}$, Tran $\mathrm{N}$, Adam T. Implementation research in health: a practical guide: Alliance Heal Policy Syst Res. World Heal; 2013.

14. Ridde V. Need for more and better implementation science in global health. BMJ Glob Health. 2016;1. https://doi.org/10.1136/bmjgh-2016-000115.

15. Schadewaldt V, McInnes E, Hiller J, Gardner A. Views and experiences of nurse practitioners and medical practitioners with collaborative practice in primary health care: an integrative review. BMC Fam Pr. 2013;14(132):1-11.

16. Willis E. Introduction: taking stock of medical dominance. Heal Sociol Rev. 2006;15(5):421-31.

17. Australian Government Department of Health. Primary care reference groups consultation - Medicare benefits schedule (MBS) review taskforce reports; 2019. [cited 2019 Mar 20]. Available from: http://www.health.gov.au/ internet/main/publishing.nsf/Content/MBSR-pcrg-consult

18. Lowe G. Integration of nurse practitioners into Australian healthcare settings: a mixed methods study of the structural, human resources, political and cultural implications for organisational change; 2014. Available from: http://arrow.monash.edu.au/hdl/1959.1/1144143

19. Dwyer T, Craswell A, Rossi D, Holzberger D. Evaluation of an aged care nurse practitioner service: quality of care within a residential aged care facility hospital avoidance service. BMC Health Serv Res. 2017;17(33). https:// doi.org/10.1186/s12913-017-1977-x.

20. Schadewaldt V, McInnes E, Hiller J, Gardner A. Experiences of nurse practitioners and medical practitioners working in collaborative practice models in primary healthcare in Australia - a multiple case study using mixed methods. BMC Fam Pract. 2016;17(99). https://doi.org/10.1186/ s12875-016-0503-2.

21. McInnes E. Review of processes for the implementation of the role of nurse practitioners in South Australia. Report for SA Health; 2008.

22. Nancarrow S, Roots A, Grace S, Moran A, Vanniekerk-Lyons K. Implementing large-scale workforce change: learning from 55 pilot sites of allied health workforce redesign in Queensland, Australia. Hum Resour Health. 2013; 11(66). https://doi.org/10.1186/1478-4491-11-66.

23. Nursing and Midwifery Board of Australia. Nurse practitioner standards of practice: ANMB; 2014. p. 1-5.

24. Medical Board of Australia. Good medical practice. A code of conduct for doctors in AustraliaMBA; 2014. p. 1-25.

25. Arbon P, Bail K, Eggert M, Gardner A, Hogan S, Phillips C, et al. Reporting a research project on the potential of aged care nurse practitioners in the Australian Capital Territory. J Clin Nurs. 2009;18.

26. Bail K, Arbon P, Eggert M, Gardner A, Hogan S, Phillips C, et al. Potential scope and impact of a transboundary model of nurse practitioners in aged care. Aust J Prim Health. 2009;15(3):232-7. https://doi.org/10.1071/PY09009.

27. Parker R, Forrest L, McCracken J, McRae I, Cox D. What primary health-care services are Australian consumers willing to accept from nurse practitioners? A national survey. Health Expect. 2014;17(5):733-40.

\section{Publisher's Note}

Springer Nature remains neutral with regard to jurisdictional claims in published maps and institutional affiliations.

Ready to submit your research? Choose BMC and benefit from:

- fast, convenient online submission

- thorough peer review by experienced researchers in your field

- rapid publication on acceptance

- support for research data, including large and complex data types

- gold Open Access which fosters wider collaboration and increased citations

- maximum visibility for your research: over $100 \mathrm{M}$ website views per year

At BMC, research is always in progress.

Learn more biomedcentral.com/submissions 